\title{
Pathogenic Variation in Colletotrichum gloeosporioides Infecting Stylosanthes spp. in a Center of Diversity in Brazil
}

\author{
S. Chakraborty, C. D. Fernandes, M. J. d' A. Charchar, and M. R. Thomas
}

First author: Commonwealth Scientific and Industrial Research Organization, Plant Industry, Long Pocket Laboratories, Indooroopilly, Queensland, CRCTPP University of Queensland, Brisbane, Australia 4072; second author: EMBRAPA-CNPGC UNESP-FCA, BotucatuSP, 18609-490 Brazil; third author: EMBRAPA-CPAC, 73301-970, Planaltina, DF, Brazil; and fourth author: CSIRO Mathematical and Information Sciences, Cleveland, Queensland Australia.

Accepted for publication 9 January 2002.

\begin{abstract}
Chakraborty, S., Fernandes, C. D., Charchar, M. J. d' A., and Thomas, M. R. 2002. Pathogenic variation in Colletotrichum gloeosporioides infecting Stylosanthes spp. in a center of diversity in Brazil. Phytopathology 92:553-562.

Pathogenic variation in Colletotrichum gloeosporioides infecting species of the tropical pasture legume Stylosanthes at its center of diversity was determined from 296 isolates collected from wild host population and selected germ plasm of S. capitata, S. guianensis, S. scabra, and $S$. macrocephala in Brazil. A putative host differential set comprising 11 accessions was selected from a bioassay of 18 isolates on 19 host accessions using principal component analysis. A similar analysis of anthracnose severity data for a subset of 195 isolates on the 11 differentials indicated that an adequate summary of pathogenic variation could be obtained using only five of these differentials. Of the five differentials, S. seabrana 'Primar' was resistant and S. scabra 'Fitzroy' was susceptible to most isolates. A cluster analysis was used to determine
\end{abstract}

ABSTRACT eight natural race clusters using the 195 isolates. Linear discriminant functions were developed for eight race clusters using the 195 isolates as the training data set, and these were applied to classify a test data set of the remaining 101 isolates. All except 11 isolates of the test data set were classified into one of the eight race clusters. Over $10 \%$ of the 296 isolates were weakly pathogenic to all five differentials and another $40 \%$ were virulent on just one differential. The unclassified isolates represent six new races with unique virulence combinations, of which one isolate is virulent on all five differentials. The majority of isolates came from six field sites, and Shannon's index of diversity indicated considerable variation between sites. Pathogenic diversity was extensive at three sites where selected germ plasm were under evaluation, and complex race clusters and unclassified isolates representing new races were more prevalent at these sites compared with sites containing wild Stylosanthes populations.

Additional keywords: geographical distribution, pathogen diversity, race composition, virulence analysis.
Species of Stylosanthes are among the most important tropical pasture legumes for large tracts of acid and infertile soils in semiarid and arid environments (34). When used in association with suitable grass species or as cut-and-carry fodder, Stylosanthes can increase meat and milk production in tropical and subtropical regions of the world where animals often suffer from a low protein diet. Stylosanthes can be easily integrated in subsistence agriculture as an alternative to expensive protein supplements.

Despite its agronomic suitability, commercial utilization of Stylosanthes spp. has been severely curtailed by anthracnose, caused by Colletotrichum gloeosporioides (Penz.) Penz. \& Sacc., which restricts its establishment, productivity, and persistence. Worldwide, anthracnose has been the single most important biotic factor in limiting the development and utilization of Stylosanthes cultivars. The genetic plasticity of $C$. gloeosporioides populations has often resulted in the development of virulent strains following the release of anthracnose-resistant cultivars. At a center of hostpathogen diversity in South and Central America, extensive pathogenic variation $(9,20)$ has led to the demise of at least five of the

Corresponding author: S. Chakraborty

E-mail address: sukumar.chakraborty@csiro.au

* The $e$-Xtra logo stands for "electronic extra" and indicates the HTML abstract available on-line contains supplemental material not included in the print edition. Additional table containing host of origin, collection site, and race cluster of C. gloeosporioides isolates obtained from Stylosanthes spp. in Brazil is available online.

Publication no. P-2002-0322-01R

(C) 2002 The American Phytopathological Society eight cultivars released (28). There is a similar history of cultivar devastation by anthracnose following their release in China, Thailand, The Philippines, and other parts of Southeast Asia (16). In Australia, cultivars of $S$. humilis Kunth, which occupied over 500,000 ha, were eliminated by anthracnose in the late 1970s, within 3 to 4 years of the disease being first reported in Australia (31). S. scabra 'Fitzroy' was restricted to low rainfall areas within 5 years of its release in 1979 due to severe damage from highly virulent races (12), and cv. Seca, highly resistant to all known races of the pathogen at the time of its release, became infected by a new race within 5 years of its release (12).

In Australia, the pathogen population has been extensively studied using morphological, molecular, and virulence analyses $(11,18,27)$. Two biotypes have been identified. Biotype A is pathogenic on all species of Stylosanthes and causes discrete lesions with gray center and dark brown margin on all aerial plant parts, whereas biotype B mainly infects $S$. guianensis, causing blight symptoms on leaf and stem. Four races have been identified within each biotype $(11,19)$. Due to the economic significance of its host species $S$. humilis, S. scabra, S. hamata, and S. seabrana, biotype A is of greatest importance in Australia.

In Colombia, Peru, and many other South American countries, S. guianensis has shown the most promise as a pasture legume and at least four of the eight cultivars released for commercial use belong to this species (28). Among other cultivars, S. capitata 'Capica' and S. macrocephala 'Pioneiro' were both released in 1983. 'Capica', a mixture of five accessions, was widely grown in Colombia due to its superior animal performance and forage quality in mixed Andropogon gayanus-S. capitata pastures (35). However, persistence of 'Capica' has been disappointing (28) due 
to its inability to compete with the established grass (32). 'Pioneiro' failed due to poor yield despite good anthracnose resistance and seed production (28). With the exception of small areas under S. guianensis 'Mineirâo', there is little commercial use of any Stylosanthes cultivar in Brazil. A new S. macrocephala-S. capitata multiline cultivar, 'Estilosantes Campo Grande' with polygenic resistance to anthracnose, has been released in 2000 (14). It is too early to assess its commercial success.

Studies on pathogen variation on isolates obtained from native $S$. guianensis have shown both qualitative and quantitative differences in virulence (29). A more recent study has described 57 pathotypes to group 104 isolates largely from Colombia using $12 S$. guianensis differentials (21). For C. gloeosporioides infecting other Stylosanthes spp., knowledge of pathogenic diversity is based on extensive field evaluation of $S$. capitata accessions in Brazil and Colombia $(15,23,25)$ and studies of wild $S$. capitata populations in Brazil (22). Eight isolate groups were identified based on the host species infected; $S$. guianensis and $S$. capitata were each infected by five different isolate groups, whereas $S$. scabra and $S$. hamata were each infected by a single isolate group (24). The pathogen population is more complex in Brazil than in Colombia, and of the $121 \mathrm{~S}$. capitata accessions, over $85 \%$ were susceptible in Brazil but less than $10 \%$ were susceptible in Colombia (25). Within Brazil, there is considerable variation in anthracnose resistance among the native $S$. capitata population at different sites (22), pointing to a different racial composition in the pathogen population at these sites. However, unlike the $S$. guianensis pathogen (21), a rigorous analysis of pathogenic diversity based on a defined host differential set is lacking for isolates infecting hosts other than S. guianensis. There is no inventory of dominant races and their geographical distribution to better design germ plasm evaluation and cultivar development programs.

In a previous attempt to classify pathogen races, the majority of Brazilian isolates originating from hosts other than S. guianensis could not be grouped using the limited Australian biotype A host differential set (9). This provides further evidence of a diverse pathogen population in Brazil and the need for new host differentials to classify this diversity.

The aims of this paper are twofold; firstly, to select a host differential set to identify dominant races of $C$. gloeosporioides infecting major Stylosanthes spp. of potential commercial significance to Brazil, and secondly, to examine the geographical distri- bution of pathogen races on wild and cultivated Stylosanthes germ plasm at selected field sites. With recent reports outlining pathogenic variation among isolates from $S$. guianensis $(20,21)$, our efforts focused on isolates originating mainly from hosts other than $S$. guianensis.

\section{MATERIALS AND METHODS}

Source of isolates. A total of 296 isolates from Brazil were used in this study (Table 1). Isolates came from three field sites, Chapadão do Sul and Campo Grande in Mato Grosso do Sul and Goiania in the Goias Province of Brazil, where promising germ plasm of Stylosanthes spp. have been under evaluation for the past 3 to 4 years. Other isolates were obtained by surveying areas in Minas Gerais and Goias provinces where Stylosanthes spp. of commercial interest are naturally distributed. Isolates were mainly obtained from S. capitata, S. scabra, and S. macrocephala with a small number from $S$. guianensis. However, it was not always possible to confirm the identity of wild Stylosanthes spp. during field surveys. Data on location, latitude, and longitude held in germ plasm banks in Brazil and Australia were utilized to locate areas of natural distribution of these species. A global positioning system (GPS II Plus; Garmin Corporation, Olathe, KS) was used during surveys to record exact location of isolate collection sites for future reference. All isolates were purified by single spore isolation.

Selection of host differentials. Nineteen accessions from five Stylosanthes spp. were selected to develop a differential set to classify isolates (Table 2). Criteria used for their selection were prior knowledge of anthracnose resistance from preliminary screenings in Brazil and Australia, differential reaction against $C$. gloeosporioides biotype A isolates in Australia, and high yield and a range of anthracnose resistance in field trials in Brazil. Eighteen Brazilian isolates obtained from $S$. capitata, S. macrocephala, and S. scabra were used to screen the 19 accessions. In preliminary tests, these isolates produced a broad range of severity on accessions of S. capitata, S. scabra, S. hamata, and S. macrocephala. All isolates were screened for pathogenic variation using a seedling bioassay (7) that consisted of growing three to four seedlings of each of the 19 accessions in riverbed soil in $40-\mathrm{mm}^{2}$ plastic pots in a greenhouse for 6 weeks. Isolates were grown on oatmeal agar for 7 to 10 days to obtain conidia for inoculum. Seedlings were sprayed to incipient runoff with a conidial suspension of

TABLE 1. Location and host of origin of Colletotrichum gloeosporioides isolates obtained from Stylosanthes spp. in Brazil

\begin{tabular}{|c|c|c|c|c|c|c|}
\hline \multirow[b]{2}{*}{ Location } & \multicolumn{5}{|c|}{ Host species } & \multirow[b]{2}{*}{ Total } \\
\hline & S. guianensis & S. scabra & S. capitata & S. macrocephala & Stylosanthes sp. & \\
\hline Campo Grande, MS & 13 & 10 & 54 & 2 & $\ldots$ & 79 \\
\hline Planaltina, DF & 1 & $\ldots$ & 3 & $\ldots$ & $\ldots$ & 4 \\
\hline Coxim, MS & 1 & $\ldots$ & $\ldots$ & $\ldots$ & $\ldots$ & 1 \\
\hline Camapuã, MS & 1 & $\ldots$ & $\ldots$ & $\ldots$ & $\ldots$ & 1 \\
\hline Chapadão do Sul, MS & 1 & 10 & 59 & 12 & $\ldots$ & 82 \\
\hline Água Branca, PI & $\ldots$ & $\ldots$ & $\ldots$ & $\ldots$ & 1 & 1 \\
\hline Demerval Lobão, PI & $\ldots$ & 4 & $\ldots$ & $\ldots$ & $\ldots$ & 4 \\
\hline São Estevão, BA & $\ldots$ & 1 & $\ldots$ & $\ldots$ & $\ldots$ & 1 \\
\hline Goiania, GO & 2 & 14 & 16 & $\ldots$ & $\ldots$ & 32 \\
\hline Paranaíba, MS & 1 & $\ldots$ & & $\ldots$ & $\ldots$ & 1 \\
\hline Guapó, GO & $\ldots$ & $\ldots$ & 1 & $\ldots$ & $\ldots$ & 1 \\
\hline Teresina, PI & $\ldots$ & 1 & 1 & $\ldots$ & $\ldots$ & 2 \\
\hline João Pinheiro, MG & $\ldots$ & $\ldots$ & $\ldots$ & $\ldots$ & 2 & 2 \\
\hline Três Marias, MG & $\ldots$ & $\ldots$ & $\ldots$ & $\ldots$ & 2 & 2 \\
\hline Paracatu, MG & $\ldots$ & $\ldots$ & $\ldots$ & $\ldots$ & 2 & 2 \\
\hline Bom Despacho, MG & $\ldots$ & $\ldots$ & $\ldots$ & $\ldots$ & 2 & 2 \\
\hline Buritis, MG & $\ldots$ & $\ldots$ & $\ldots$ & $\ldots$ & 29 & 29 \\
\hline Alvorada do Norte, GO & $\ldots$ & $\ldots$ & $\ldots$ & $\ldots$ & 3 & 3 \\
\hline Cabeceiras, GO & $\ldots$ & $\ldots$ & $\ldots$ & $\ldots$ & 33 & 33 \\
\hline Padre Bernardo, GO & $\ldots$ & $\ldots$ & $\ldots$ & $\ldots$ & 1 & 1 \\
\hline Diamantina, $\mathrm{MG}$ & $\ldots$ & $\ldots$ & $\ldots$ & $\ldots$ & 13 & 13 \\
\hline Total & 20 & 40 & 134 & 14 & 88 & 296 \\
\hline
\end{tabular}


$10^{6}$ conidia per $\mathrm{ml}$ and incubated in a saturated environment at $25^{\circ} \mathrm{C}$ for $48 \mathrm{~h}$. Ten days after inoculation, plants were visually assessed for disease severity on a 10-point rating scale $(0=$ disease-free, $1=1$ to $3 \%$ leaf area diseased, $2=4$ to $6 \%, 3=7$ to $12 \%, 4=13$ to $25 \%, 5=26$ to $50 \%, 6=51$ to $75 \%, 7=76$ to $87 \%, 8=88$ to $94 \%$, and $9=95$ to $100 \%$ ) (6). The bioassay was repeated twice to obtain data on three replicate runs.

The multivariate structure of the isolates was examined by principal component analysis. Disease ratings on each host accession were regarded as variables, and each isolate was regarded as an observation. Principal component analysis was used to generate composite scores, which are linear combinations of the ratings on each accession. Principal component scores have the maximum variance of any set of uncorrelated normalized linear combinations of the original ratings. Each accession was dropped in turn, and the principal components were recomputed. The first four principal components scores were then rotated and translated into maximum conformity with the principal components based on the full set of accessions. This transformation was achieved with Procrustes rotations (13). For each accession, the sum of squared distance between the new configuration (based on the reduced differential set) and the original four-component configuration was calculated and expressed as a percentage of the sum of squares of the original configuration. This "stress statistic" was calculated as each accession was dropped in turn. The accession with the minimum stress was then dropped permanently, and each of the remaining accessions was dropped in turn. The process was repeated in a stepwise fashion, eliminating one accession (corresponding to minimum stress) at each step. The minimum stress was plotted against the number of accessions excluded in each step. The remaining accessions were included in a putative differential set.

The SAS (SAS Institute, Cary, NC) and S-plus (Statistical Sciences, Seattle, WA) software packages were used for all analyses.

Pathogenic variation. Pathogenicity assays were carried out on 6-week-old seedlings grown in a greenhouse, and three to five seedlings were maintained for each differential. Isolates were screened either at Campo Grande, Mato Grosso do Sul, or at Planaltina, Brasilia DF, using the newly selected differential set consisting of 11 accessions. Seedlings were inoculated and assessed using the 0 to 9 point scale as before. Data for isolates obtained from S. guianensis, S. scabra, S. capitata, and S. macrocephala (Table 1) came from at least two replicate runs of the bioassay, whereas data for isolates from the unidentified Stylosanthes sp. came from a single inoculation of three to five seedlings. Due to limited greenhouse space, only a small number of isolates could be screened at any given date. Eight isolates, CG30, CG41, CG205, PL404, PL407, CG173, CG135, and PL592, were designated as reference isolates and one or more of the reference isolates were included at each inoculation for comparison.

Data analysis for race assignment. A discriminant function analysis was used to assign isolates into races. In this analysis, a

TABLE 2. Accessions of Stylosanthes spp. used in inoculation studies with 18 selected isolates of Colletotrichum gloeosporioides to select a putative differential set of 11 accessions (underlined) for the screening of further isolates

\begin{tabular}{ll}
\hline Host species & CNPGC accession number ${ }^{\mathrm{a}}$ \\
\hline $\begin{array}{l}\text { S. macrocephala } \\
\text { S. capitata }\end{array}$ & $\underline{1511}$ (cv. Pioneiro) and $\underline{1582}$ \\
S. scabra & $\underline{1081}, \underline{1084}, 1086,1094,1096,1173,1180,1536$ \\
& $\underline{1496}$ (cv. Fitzroy), 1498 (CPI 93116), 1499 \\
S. seabrana & $\underline{1588}$ (cv. Primar) 1 (cv. Seca), 1532 (rr 94-3) \\
S. guianensis & $\begin{array}{c}1543 \text { (cv. Schofield), } 1545 \text { (cv. Endeavour), 1546 } \\
\text { (cv. Cook) }\end{array}$ \\
\hline
\end{tabular}

${ }^{a}$ Figure in parenthesis is the cultivar name or number assigned to an accession in another country. training set of data on individuals with known race membership was used to develop linear discriminant functions (LDF). These functions were then used to classify individuals of unknown grouping. As data on disease severity of the 296 isolates became available, isolates were allocated to the two data sets. Set 1 (training set) contained the first 195 isolates tested using the seedling bioassay and included the 18 isolates used in differential selection. Set 2 (test set) contained the remaining 101 isolates and included a subset of 12 isolates randomly selected from set 1 .

The multivariate response across differentials was explored using principal component analysis to determine the number of independent dimensions needed to account for variation in the response profile. Data from set 1 were averaged over replicates and dates to form a mean value for each isolate. Disease ratings on each differential were considered separate variates and data were log-transformed to stabilize variance. Principal component scores were calculated from the resulting data matrix of 195 observations (isolates) and 11 variates (differentials).

Data on set 1 isolates were averaged over replicates and inoculation dates, log-transformed, and subjected to cluster analysis with a complete linkage algorithm (17). To determine the number of clusters, the cluster tree was examined with the number of clusters varying from 2 to 15 , and the proportional reduction in residual sum of squares $\left(R^{2}\right)$ was plotted against the number of clusters.

LDF were developed using set 1 data to classify isolates in set 2. The clusters obtained for set 1 were used to define race clusters, and membership of the set 2 isolates to these races was predicted using the LDF. This way, the training data set was independent of the test set. Data for the 12 common isolates in sets 1 and 2 came from two separate bioassays. Data were log-transformed and averaged across replicates and inoculation dates before allocation to race clusters. Isolates within the 95th percentile of the distribution of within-cluster Mahalanobis distance for a given race cluster were classified as a member of that race cluster. Isolates that did not meet this distance criterion for any cluster remained unclassified.

Cross-validation of race clusters. To test the robustness of the eight race clusters, unbiased estimates of classification success were obtained with a cross-validation technique. Data from both

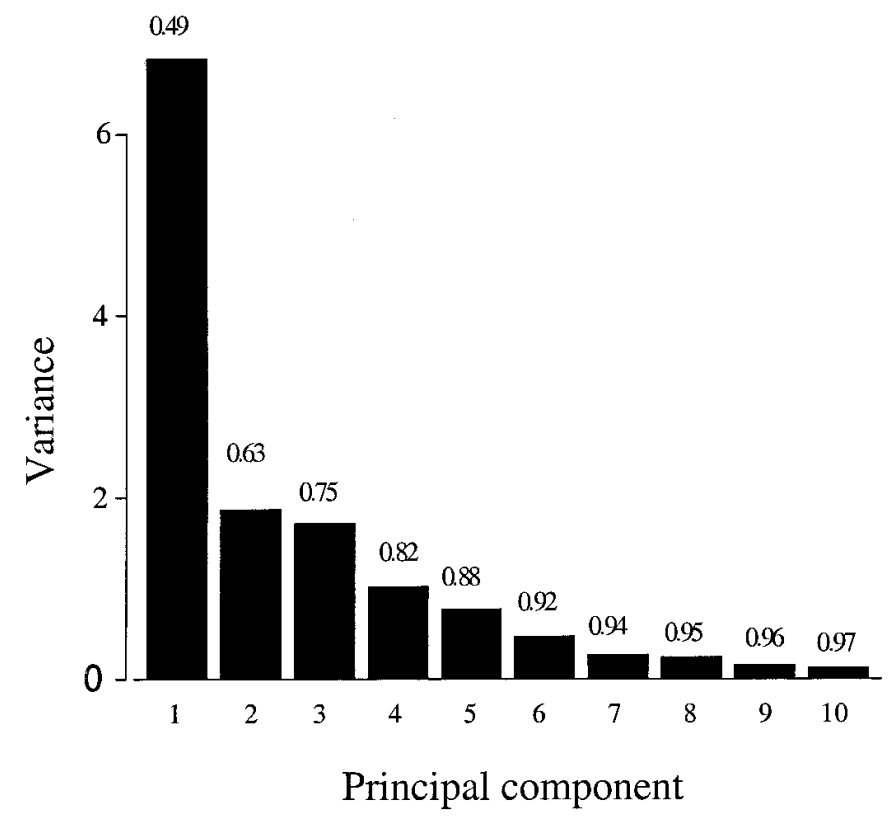

Fig. 1. Scree plot of principal components from an analysis of anthracnose severity of 18 Colletotrichum gloeosporioides isolates inoculated onto 19 Stylosanthes spp. accessions to select a differential set. The value on each bar shows the cumulative proportion of variation explained. 
sets were averaged over replicates to form mean scores for each of the five differentials for each race cluster and inoculation date. Observations corresponding to the first date were excluded from the data set, and LDF were developed using the remaining data to predict race cluster assignment of the excluded observations. The excluded data were reinstated, data corresponding to the second date were excluded, and the same process was repeated until all dates were excluded in turn. Classification success was calculated as the percentage of dates when a given race cluster was correctly classified as the same race cluster. We have previously used a linear discriminant analysis and cross-validation technique to classify Australian isolates into races (11) and further details can be obtained from this work.

Geographical distribution of race clusters. Shannon's index was used to estimate diversity in the pathogen population at six selected sites using the following formula: $h=-\Sigma\left(n_{i} / n\right) \log _{10}\left(n_{i} / n\right)$, where $n_{i}$ is the frequency of the $i$ th cluster and $n$ is the sample size (1). For three of these sites, Buritis $(n=29)$, Cabeceiras $(n=33)$, and Diamantina $(n=13), C$. gloeosporioides isolates originated from wild Stylosanthes populations. At Campo Grande $(n=79)$, Chapadão do Sul $(n=82)$, and Goiania $(n=32)$, isolates were collected from selected Stylosanthes germ plasm under evaluation at these sites.

\section{RESULTS}

Selection of host differentials. The 18 selected isolates caused discrete lesions on some or all host plants, including accessions of $S$. guianensis. Lesions of varying size were produced on leaf, stem, petiole, bract, and seed coat. These were typically elongated, circular, oval, or irregular, with a definite margin surrounding a central necrotic area. The margin ranged from $<1 \mathrm{~mm}$ to several millimeters in width and was dark brown to black in color. In more susceptible accessions of S. capitata in particular, the dark margin was often more extensive. The central necrotic tissue was typically gray, often covered with black acervuli arranged in concentric circles. Under high relative humidity, lesions with abundant acervuli appeared salmon-colored with the production of massive amounts of conidia. Lesions coalesced to cover large irregular areas under more severe infection conditions.

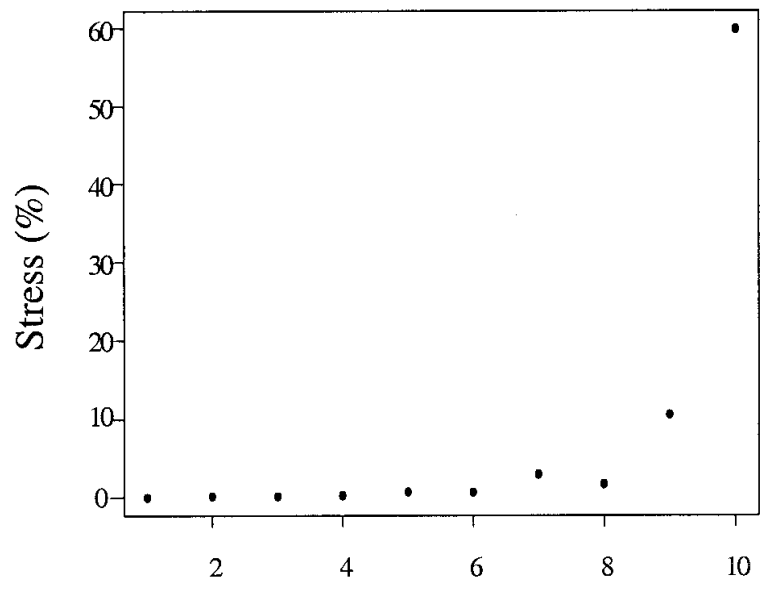

\section{Accessions dropped}

Fig. 3. Increasing stress, as determined by the "stress statistic," from the dropping of an increasing number of Stylosanthes spp. accessions inoculated with 18 Colletotrichum gloeosporioides isolates to select a differential set. The stress statistic is calculated as follows: principal component scores are computed for data on all accessions; each accession is dropped in turn, and the principal components recomputed; and the stress statistic is the sum of squared distance between the new configuration (based on the reduced differential set) and the original configuration expressed as a percentage of the sum of squares of the original configuration.

\section{Component 1}

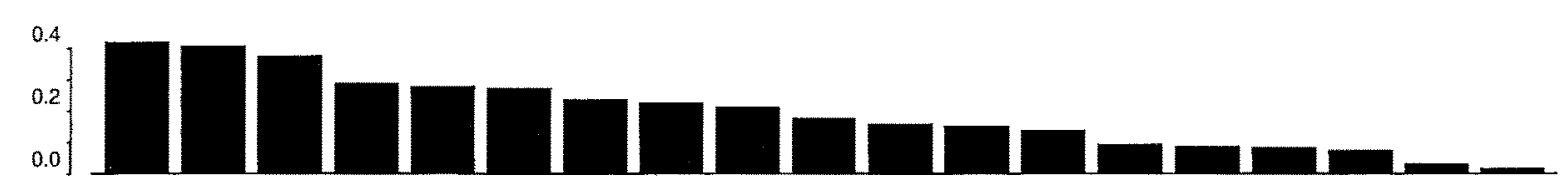

Component 2
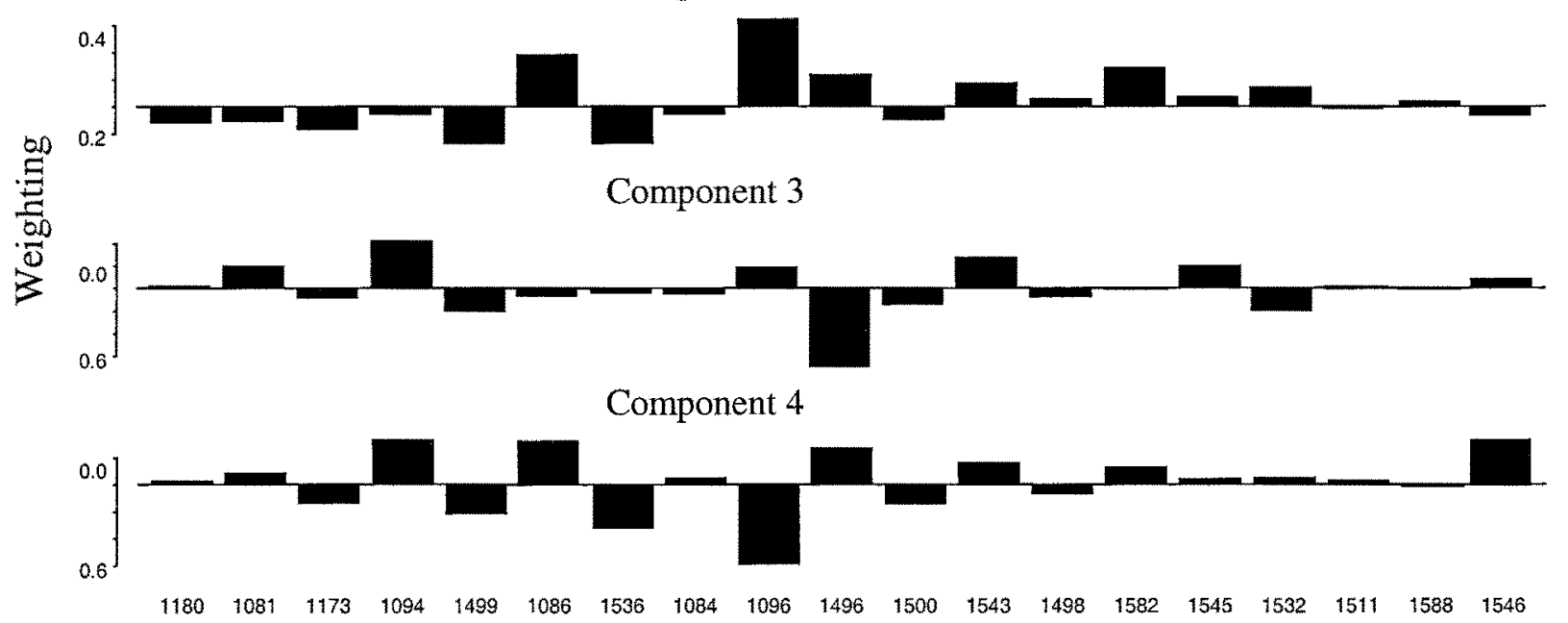

\section{Stylosanthes accession}

Fig. 2. Weighting of the first four principal components from an analysis of anthracnose severity of 18 Colletotrichum gloeosporioides isolates inoculated on 19 Stylosanthes spp. accessions to select a differential set. 
A principal component analysis of the severity data on 18 isolates across all 19 accessions showed that the first four and six components explained over 80 and $90 \%$ of the total variance, respectively (Fig. 1). The first four components may be used to demonstrate contribution of individual accessions to the principal components. The first eigenvector shows a positive weight on each accession (Fig. 2). This may be interpreted as an aggressiveness component, indicating that the most important difference between isolates is that some are aggressive on all accessions, and some are not aggressive on any. The second component is large and positive for accessions CNPGC 1096, 1086, 1582, and 1496, but is large and negative on accessions 1536 and 1499. It might be interpreted as measuring the differential impact on 1536 and 1499. The third component is large and negative on 1496 but positive on 1094 and 1543. It might be regarded as a contrast in resistance in these accessions. The fourth component contrasts the resistance of accessions 1096 and 1536 with differentials 1546, 1094, 1086, and 1496.

Using the stress statistic, accessions with minimum stress were eliminated one at a time in a stepwise analysis. Removal of six accessions does not make any difference in the stress statistic and the removal of up to eight only causes less than $3 \%$ stress, but dropping the ninth accession sharply increases the stress statistic to $10.6 \%$ (Fig. 3). This indicates that 8 of the 19 accessions can be discarded. We have further examined the contribution of accessions toward isolate discrimination by plotting the 18 isolates in the space of the first two principal components computed for 18 accessions after dropping only one, and again after dropping the eight accessions (data not shown). There is a strong agreement between the configuration based on 18 accessions and the reduced set of 11 accessions, indicating that little of the information in the first two principal components has been lost by discarding the eight accessions.

A putative differential set consisting of the 11 remaining accessions was selected for screening of all isolates. This contained two S. macrocephala, four $S$. capitata, two $S$. scabra, one S. seabrana, and two $S$. guianensis accessions (Table 2).

Pathogenic variation. Disease severity data on 195 isolates provided an opportunity to further examine the contribution of the 11 putative differentials in discriminating the isolates. A principal component analysis was carried out on the severity data matrix of 195 observations (isolates) and 11 variates (differentials). In this analysis, the first six and eight principal components explained $>80$ and $>90 \%$ of the variation, respectively (output of analysis not given). Only 5 of the 11 putative differentials, S. macrocephala 1582, S. capitata 1084, S. seabrana cv. Primar, $S$. scabra cv. Fitzroy, and $S$. guianensis cv. Cook, had large positive or negative loadings on the first eight principal components. This indicated that the variation among the 195 isolates of $C$. gloeosporioides could be adequately explained by these five differentials. This reduced set of five differentials was used in all further analyses.

Clustering of the 195 set 1 isolates showed that incremental improvement in $R^{2}$ was most pronounced $(15 \%)$ as the number of clusters increased from two to three (Fig. 4). $R^{2}$ increased by 3.1 and $5 \%$ with each additional cluster between four and eight. Beyond eight, the incremental rise in $R^{2}$ with each additional cluster was less than $3 \%$. Eight clusters were selected using $R^{2}>3 \%$ as the cut-off point to represent the natural groups among set 1 isolates. The eight clusters accounted for $74 \%$ of the variation.

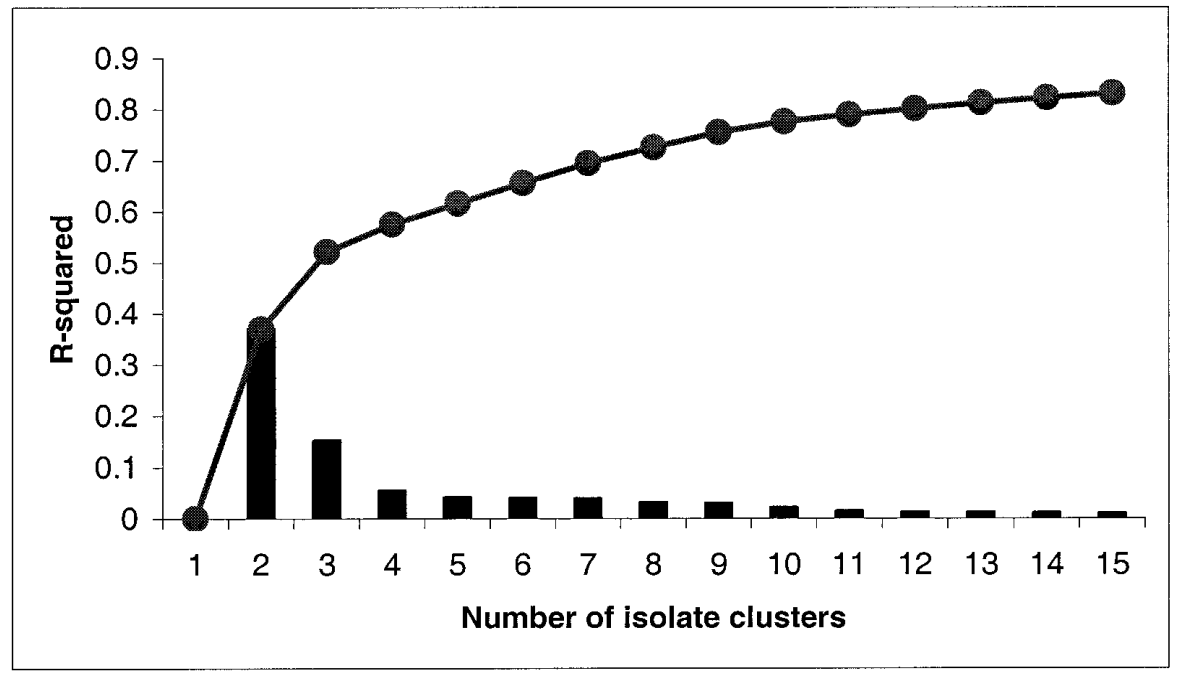

Fig. 4. Cumulative (line) and incremental (bar) improvements in the coefficient of determination $\left(R^{2}\right)$ when the number of clusters is increased from 2 to 15 for 195 isolates of Colletotrichum gloeosporioides, causing anthracnose on five differential host genotypes of Stylosanthes spp.

TABLE 3. Mean and standard error (in parenthesis) of disease severity $(\ln [x+1])$ on five host differentials of Stylosanthes spp. for 195 set 1 isolates of Colletotrichum gloeosporioides representing eight race clusters

\begin{tabular}{|c|c|c|c|c|c|c|}
\hline \multirow[b]{2}{*}{ Race cluster } & \multirow[b]{2}{*}{ Number of isolates } & \multicolumn{5}{|c|}{ Anthracnose severity on differential } \\
\hline & & S. capitata 1084 & S. scabra Fitzroy & S. macrocephala 1582 & S. guianensis Cook & S. seabrana Primar \\
\hline 1 & 29 & $0.04(0.02)$ & $0.08(0.02)$ & $0.17(0.06)$ & $0.25(0.06)$ & $0.01(0.01)$ \\
\hline 4 & 33 & $1.50(0.05)$ & $2.00(0.04)$ & $0.33(0.04)$ & $0.42(0.07)$ & $0.35(0.05)$ \\
\hline 5 & 14 & $0.70(0.14)$ & $1.61(0.07)$ & $1.24(0.09)$ & $0.17(0.08)$ & $0.27(0.08)$ \\
\hline 6 & 16 & $0.50(0.06)$ & $1.40(0.08)$ & $0.63(0.08)$ & $0.64(0.06)$ & $0.68(0.07)$ \\
\hline
\end{tabular}




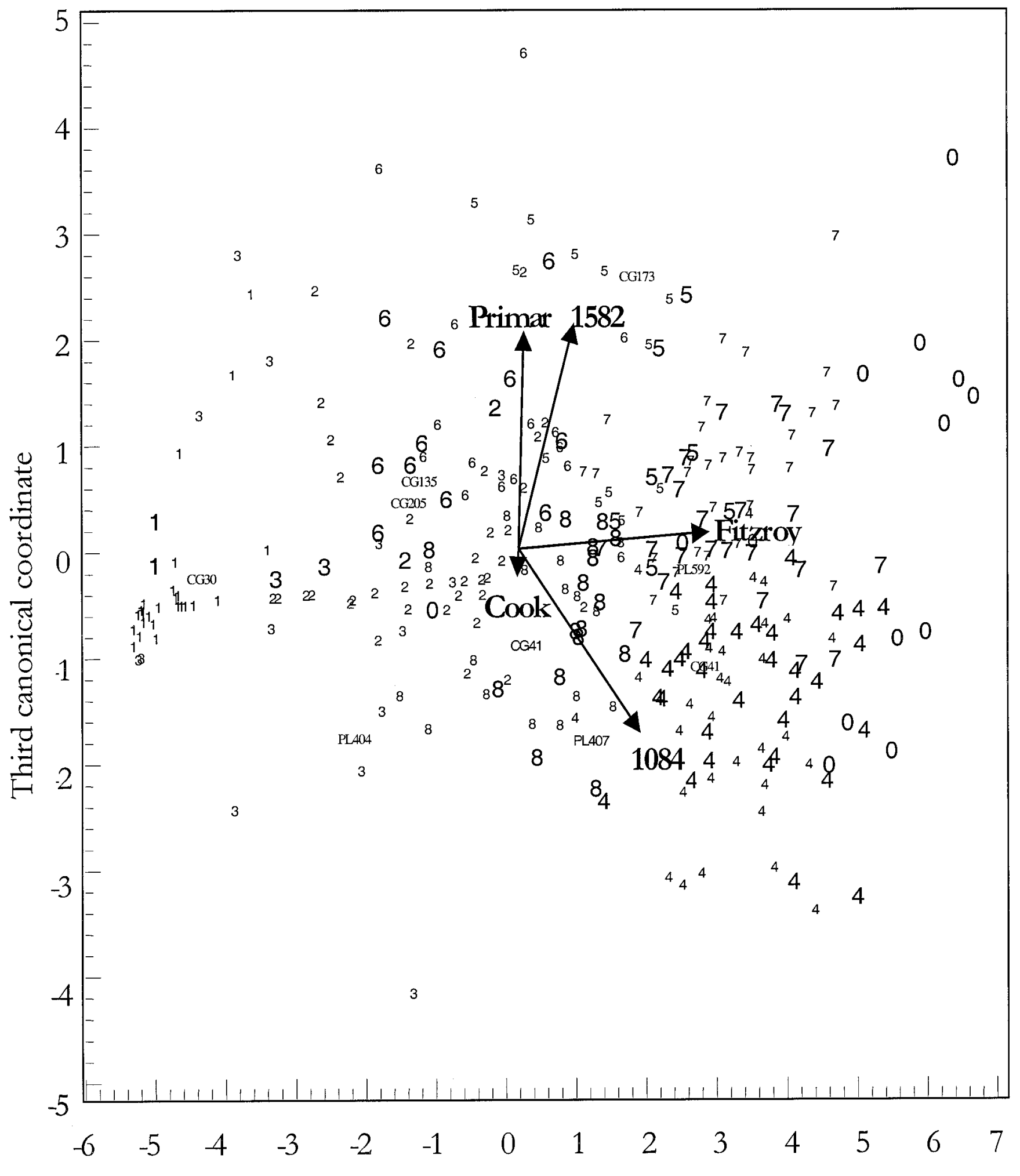

First canonical coordinate

Fig. 5. Classification of 101 isolates of Colletotrichum gloeosporioides into race clusters (large numerals, 1 through 8) using linear discriminant functions developed from a training data set on disease severity of 195 isolates (small numerals) on differential host genotypes of Stylosanthes spp. Unclassified isolates are represented by a zero (large numeral). The four original axes (arrows) have been projected onto the plot to relate the log-transformed scores on the differentials to the two canonical coordinates. The point of origin of the arrows represents the overall mean severity of isolates in the training data set. The length of each arrow represents the change in canonical coordinates given a unit change from the mean score for each differential. For clarity, only some of the reference isolates have been labeled. 
The characteristics of isolates in the eight clusters can be summarized from their mean severity on the five differentials (Table 3 ). Using $\ln (x+1)>1$ (untransformed disease severity rating $>2$ ) to denote virulence, cluster 1 contained 29 weakly virulent isolates with very low to low severity on all five differentials. Isolates in all other clusters, except cluster 3, were at least virulent on $S$. scabra 'Fitzroy'. Isolates in clusters 2, 6, and 8 were only virulent on 'Fitzroy', but show different levels of aggressiveness toward the other four differentials. Cluster 2 isolates were least aggressive, and cluster 6 isolates were most aggressive on 1582, 'Cook', and 'Primar'. Isolates in cluster 8 were similar to cluster 2 isolates, except more aggressive on 1084. The 15 isolates in cluster 3 were only virulent on $S$. guianensis cv. Cook. Isolates in clusters 4 and 7 were virulent on 'Fitzroy' and 1084, and cluster 7 isolates were more aggressive on 1582, 'Cook', and 'Primar'. Cluster 5 isolates were virulent on 'Fitzroy' and 1582. None of the isolates were virulent on 'Primar'.

LDF were developed using the eight clusters in set 1 as the training data set, which were then used to classify the 101 isolates in set 2. Although the eight clusters exist in an eight-dimensional space corresponding to severity on the eight differentials, the first two canonical coordinates explain the maximum variation among clusters. A projection of the first and third canonical covariates show that clusters 1,4 , and 7 are reasonably well separated, although without clear-cut boundaries (Fig. 5). Clusters 2, 6, and 8 are more difficult to separate, because the main difference between these clusters is in their aggressiveness toward four of the five differentials used.

Most (90) of the 101 isolates in set 2 could be classified into the eight existing race clusters using LDF. Of these, four isolates were classified in cluster 2, two isolates in cluster 3,33 isolates in cluster 4, six isolates in cluster 5, 10 isolates in cluster 6, 23 isolates in cluster 7, and 12 isolates in cluster 8. Eleven isolates could not be classified using the LDF. Using $\ln (x+1)>1$ to denote virulence, these unclassified isolates represent six potential new races with unique virulence combinations on the five differentials. Isolate CG94 is virulent on 'Fitzroy' and 'Cook'; isolate CG318 is virulent on 1084, 'Fitzroy', and 'Cook'; isolates CG55 and CG102 are virulent on 1084, 1582, and 'Fitzroy'; isolate CG227 is virulent on all except 'Cook'; isolates CG6, CG10, CG48, CG215, and CG240 are virulent on all differentials except 'Primar'; and isolate CG19 is virulent on all five differentials (data not shown).

Of the 12 isolates common to both data sets, isolates CG169 and CG251 were correctly assigned to their respective race clusters using the LDF. Isolates CG66, CG213, and CG252 were classified in race clusters 2,6 , and 8 in the two data sets. These three race clusters only differ in aggressiveness (Table 3 ). Isolates CG41, CG64, CG65, and CG249 were virulent on either 'Fitzroy' only or on 'Fitzroy and 1084 in the two data sets, thereby resulting in their misclassification. However, the overall difference in disease severity for these isolates between the two data sets was relatively small (data not shown). Similarly, small differences in severity between the data sets for isolate CG29 resulted in its misclassification from cluster 1 to cluster 5. Isolates CG22 and CG212, classified in cluster 2 in the training set, remained unclassified in the test data set, where CG22 was virulent on all differentials except 'Primar', and CG212 was virulent on 1084 and 'Primar'. For CG212, the difference in severity on 1084, 'Primar', and 'Fitzroy' was minor between the two data sets. This was not the case with CG22, and this isolate requires further investigation.

Cross-validation of race clusters. The classification success of the eight race clusters was determined with a cross-validation procedure in which data for each date were removed in turn. Over $91 \%$ of the time, race cluster 1 was classified as race cluster 1 (Table 4). All other race clusters, except 5, were correctly classified more than $60 \%$ of the times. Race cluster 5 was only correctly classified $48 \%$ of the times, but it was not misclassified to any particular race cluster. Clusters 4 and 7 remained unclassified for over $30 \%$ of the times.

Geographical distribution of race clusters. The six selected field sites represented 268 of the 296 isolates examined in this study. Race clusters 2, 4, 5, and 7 were found at five of the six sites, but none was ubiquitous (Fig. 6). Shannon's index for pathogenic diversity for sites with wild Stylosanthes population ranged from 0.51 at Cabeceiras, 0.68 at Buritis, and 0.74 at Diamantina. Shannon's index for the germ plasm evaluation sites was 0.68 at Goiania, 0.72 at Chapadão do Sul, and 0.88 at Campo Grande. Ten of the eleven complex isolates that could not be classified into any race cluster were from the germ plasm evaluation sites (Fig. 6), and all three of the more complex race clusters (race clusters 6, 7, and 8 ) were present at each of these sites. In contrast, race clusters 6 and 8 were absent from two of the three sites with wild Stylosanthes.

\section{DISCUSSION}

To our knowledge, this is the first published report on the development of a host differential set to analyze pathogenic variation in C. gloeosporioides infecting species of Stylosanthes other than $S$. guianensis at a center of diversity in Brazil. We have used five host differentials to classify pathogenic variation in 296 isolates collected from wild Stylosanthes populations and selected germ plasm of S. capitata, S. scabra, S. guianensis, and S. macrocephala from field sites spanning six states of Brazil. S seabrana 'Primar' was resistant, and S. scabra 'Fitzroy' was susceptible to most isolates. All except 11 isolates were classified into one of the eight race clusters developed in this study using LDF. Over $10 \%$ of the isolates were weakly pathogenic to all differentials and another $40 \%$ were virulent on just one differential. The unclassified isolates represent six potential new races with unique virulence combinations, of which one isolate is virulent on all five differentials. The robustness of the eight race clusters is clear from

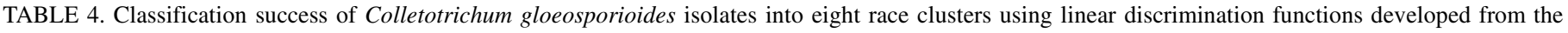
severity of these isolates on a set of eight Stylosanthes spp. differentials

\begin{tabular}{|c|c|c|c|c|c|c|c|c|c|c|c|}
\hline \multirow{2}{*}{$\begin{array}{l}\text { Race } \\
\text { cluster }\end{array}$} & \multirow{2}{*}{$\begin{array}{c}\text { Number of } \\
\text { repeats }^{\mathrm{a}}\end{array}$} & \multicolumn{9}{|c|}{ Classified as race cluster } & \multirow[b]{2}{*}{ Success $(\%)^{\mathrm{b}}$} \\
\hline & & 1 & 2 & 3 & 4 & 5 & 6 & 7 & 8 & Unclassified & \\
\hline 1 & 61 & 56 & 0 & 4 & 0 & 1 & 0 & 0 & 0 & 0 & 91.8 \\
\hline 2 & 50 & 0 & 34 & 0 & 1 & 2 & 3 & 0 & 8 & 2 & 68 \\
\hline 3 & 17 & 1 & 1 & 14 & 0 & 0 & 1 & 0 & 0 & 0 & 82.3 \\
\hline 4 & 80 & 0 & 6 & 0 & 50 & 0 & 0 & 10 & 2 & 12 & 62.5 \\
\hline 5 & 25 & 0 & 5 & 0 & 0 & 12 & 0 & 5 & 2 & 1 & 48 \\
\hline 6 & 30 & 0 & 0 & 0 & 1 & 0 & 25 & 1 & 3 & 0 & 83.3 \\
\hline 7 & 60 & 0 & 0 & 0 & 2 & 2 & 4 & 39 & 1 & 12 & 65 \\
\hline 8 & 48 & 0 & 2 & 0 & 5 & 3 & 1 & 3 & 31 & 3 & 64.6 \\
\hline
\end{tabular}

a Total number of times the bioassay is repeated for isolates in a given race cluster.

${ }^{\mathrm{b}}$ Classification success is the percentage of times a given race cluster is correctly classified into the same race cluster. 
classification success of between 60 and $90 \%$ for seven of the eight clusters. There was considerable variation between six sites, representing over $90 \%$ of the isolates studied. Compared with sites of wild Stylosanthes population, complex race clusters were more prevalent at sites where selected germ plasm had been under evaluation, and 10 of the 11 unclassified isolates came from these evaluation sites.

This work builds on previously published and unpublished work, demonstrating a diverse pathogen population in South America. Recently, classification and identification of races has been standardized with the publication of a host differential set for the pathogen population infecting $S$. guianensis (21). Although there has been ample evidence of pathogenic variation among $C$. gloeosporioides infecting species other than S. guianensis $(15,23-$ 25 ), information on pathogen races and their geographical distribution is not available. This is mainly due to the lack of a welldefined set of host differentials capable of identifying the different races. The grouping based on host species (24) is of limited value, because it does not allow the identification of individual races capable of infecting specific accessions and cultivars. Without a host differential set, information on the structure and dynamics of pathogen races following the release of cultivars such as Capica has not been possible. The host differential set described in this paper and the summary analysis of race clusters provide valuable tools for future work.

We have demonstrated considerable variation in the pathogen population between field sites. Pathogenic and genetic variation between Colombian field sites has been reported for $C$. gloeosporioides infecting $S$. guianensis (21) and S. capitata (25). When selections from an Australian S. scabra breeding program
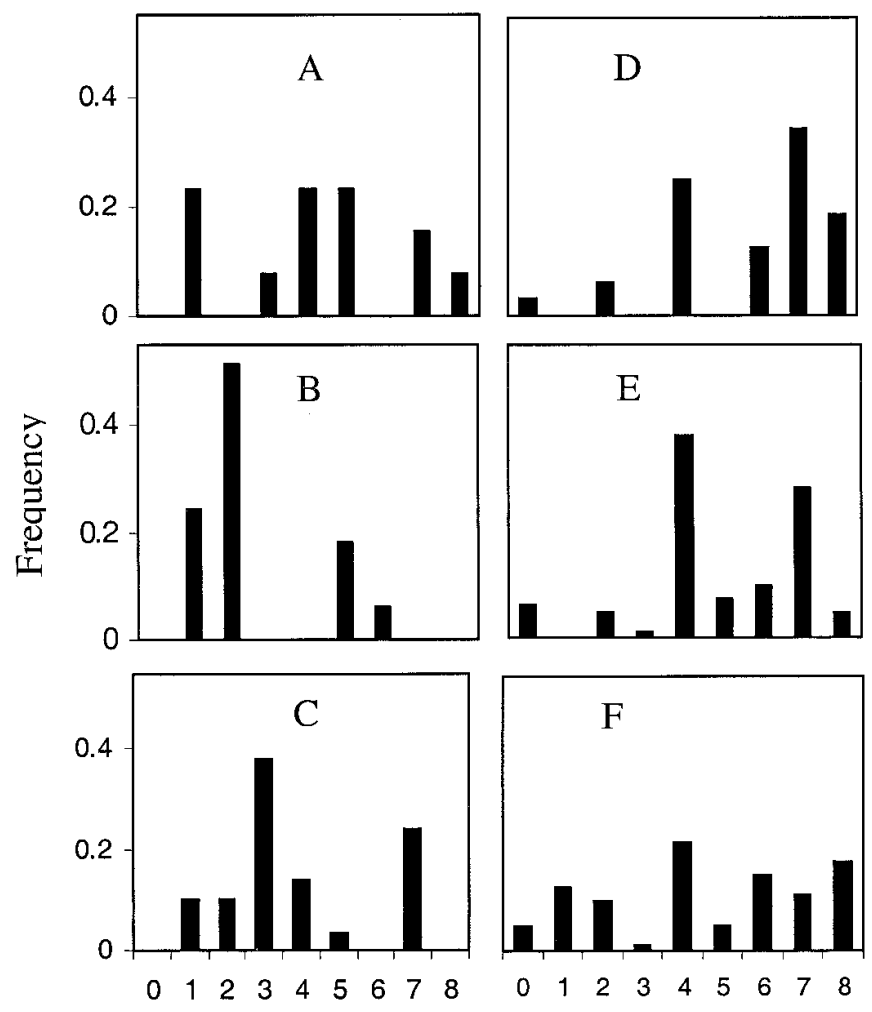

\section{Race cluster}

Fig. 6. Frequency of Colletotrichum gloeosporioides race clusters obtained from wild Stylosanthes populations at A, Diamantina, B, Cabeceiras, and C, Buritis and from selected Stylosanthes germ plasm under evaluation at $\mathbf{D}$, Goiania, E, Chapadão do Sul, and F, Campo Grande. Race cluster zero represents isolates that could not be classified into any of the existing eight race clusters identified in this study. were evaluated in Brazil, many performed better at Campo Grande than at Planaltina due to a more diverse pathogen population at Planaltina (5). Only four isolates from Planaltina were included in the present work: three isolates were from three different race clusters and one isolate was unclassified. A Shannon's index of diversity was not calculated for Planaltina due to the small sample size. Of the three germ plasm evaluation sites, the highest Shannon's index was at Campo Grande followed by Chapadão do Sul and Goiania. The index was similar or greater than the wild Stylosanthes sites, and the more complex race clusters (race clusters 6, 7, and 8) were more prevalent at the germ plasm evaluation sites. Ten of the eleven unclassified isolates representing potential new races were found at these sites. In common with studies on other pathogens $(2,30)$, our results point to pathogen adaptation in response to new sources of resistance at the germ plasm evaluation sites.

Among the three sites with wild Stylosanthes examined in our study, which included Buritis and Diamantina from Minas Gerais, the greatest pathogenic variation was found in Diamantina. A previous study also showed that anthracnose resistance among progeny of native $S$. capitata population was more diverse at Diamantina than at another site in Minas Gerais (22). Although grazing management and possible differences in microclimate have been suggested, the reason for this difference in diversity is not clear. Our results point to a diversification in the pathogen population in response to the diversity in host population at Diamantina. In bean anthracnose, most of the wild Argentinean isolates of $C$. lindemuthianum were only virulent on the Andean cultivars and few isolates carried virulence factors to overcome specific resistance genes used in bean breeding (33). This suggests that in the absence of race-specific resistance, host-pathogen coevolution at a center of diversity may favor simple races due to fitness cost associated with virulence $(3,26)$. However, due to interactions with pathogen and host life history variations, hostpathogen coevolution in natural communities that operate under very long timescales can be erratic (4). Life history traits of $C$. gloeosporioides infecting Stylosanthes such as a restricted host range (36) and a less than $10 \mathrm{~m}$ range for splash-dispersed conidia (8) prevent a rapid distribution of isolates across large geographical areas. This explains the localized distribution of unclassified isolates that have arisen in response to the different sources of resistance at the germ plasm evaluation sites. This situation is likely to change with the expected spread of new Stylosanthes cultivars, which will disseminate this seedborne pathogen. The number of isolates examined from wild Stylosanthes population in our work is relatively small and more extensive sampling over number of seasons is necessary for more realistic examination of coevolution.

Genetic studies using selection-neutral molecular markers have reported extensive diversity in the South American $C$. gloeosporioides population infecting wild and cultivated Stylosanthes $(9,20,27)$. In contrast, 285 of the 296 isolates were classified into eight race clusters in the current study. Although the relatively low level of pathogenic diversity appears smaller than hypothesized based on the genetic diversity data, this is consistent with the lack of widespread distribution of anthracnose-resistant cultivars. This difference between genetic and pathogenic diversity is not unexpected because earlier findings from both Brazil and Australia have shown only weak association between genetic and pathogenic groups, and races of this pathogen can arise convergently from different genetic lineages $(10,21)$.

Future research will focus on developing an inventory of races for different regions in Brazil using the host differentials and the methodology for race classification developed in this work. This information can be used to target cultivars with specific resistance to match prevailing races in a given region. However, performance from small plot trials at selected locations does not guarantee continued success of a cultivar. Rapid changes in the 
Australian pathogen population following the release of S. scabra cultivars have been reported (12). With the widespread use of $S$. scabra 'Seca' in Australia, more aggressive forms of the matching race have appeared with an increasing frequency (10). The situation is more complex in Brazil, where other pests (23) and management constraints (28) influence the commercial success of Stylosanthes. This emphasizes the need for continued monitoring of the pathogen population following the release of new cultivars such as 'Estilosantes Campo Grande'. Some components of this multiline currently show a low level of anthracnose at Chapadão do Sul.

Pathogenic diversity is expected to intensify with more widespread use of commercial cultivars in Brazil. Many of the accessions included in the 11 putative differentials are among materials currently being evaluated in regional trials for possible cultivar development. The reduced set of five differentials adequately describes pathogenic variation in the isolate collection examined here. However, we have continued to use all 11 putative differentials in screening isolates from other geographical areas. This way, as cultivars with specific resistance become widespread, comparisons can be made with existing and new races that may evolve in the future. New LDF can be developed for the extended differential set for this purpose. The majority of isolates in this study come from only three states in Brazil; hence, the number of race clusters should not be viewed as absolute. The number, structure, and membership of the race clusters will become clearer as pathogenicity data on more isolates are progressively added and analyzed.

\section{ACKNOWLEDGMENTS}

Financial assistance was provided by the Australian Centre for International Agricultural Research, Co-operative Research Centre for Tropical Plant Pathology, and the University of Queensland. We thank R. Perrott, S. Clapham, A. K. Akimoto, and R. M. Gonçalves for technical assistance.

\section{LITERATURE CITED}

1. Brown, J. E., Zar, J. H., and van Ende, C. 1990. Field and Laboratory Methods for General Ecology. 3rd ed. W. C. Brown Publishers, Dubuque, IN.

2. Brown, J. K. M., Foster, E. M., and O'Hara, R. B. 1997. Adaptation of powdery mildew populations to cereal varieties in relation to durable and non-durable resistance. Pages 119-138 in: The Gene-for-Gene Relationship in Plant-Parasite Interactions. I. A. Crute, E. A. Holumb, and J. J. Burdon, eds. CAB International, Wallingford, UK.

3. Burdon, J. J. 1993. The structure of pathogen populations in natural plant communities. Annu. Rev. Phytopathol. 31:305-323.

4. Burdon, J. J., and Thrall, P. H. 1999. Spatial and temporal patterns in coevolving plant and pathogen associations. Am. Nat. 153(suppl.): S15-S33.

5. Cameron, D. F., Charchar, M. J. d'A., Fernandes, C. D., Kelemu, S., and Chakraborty, S. 1997. Biodiversity, epidemiology and virulence of Colletotrichum gloeosporioides. III. Field evaluation of Stylosanthes species for anthracnose resistance in their center of diversity. Trop. Grassl. 31:402-407.

6. Chakraborty, S. 1990. Expression of quantitative resistance of Colletotrichum gloeosporioides in Stylosanthes scabra at different inoculum concentrations and day-night temperature. Aust. J. Agric. Res. 41:89100.

7. Chakraborty, S., and Jones, P. N. 1993. A rapid bioassay for the assessment of pathogenic variation in Colletotrichum gloeosporioides infecting Stylosanthes scabra. Plant Dis. 77:1016-1020.

8. Chakraborty, S., Pangga, I. B., Lupton, J., Hart, L., Room, P. M., and Yates, D. 2000. Production and dispersal of Colletotrichum gloeosporioides spores on Stylosanthes scabra under elevated $\mathrm{CO}_{2}$. Environ. Pollut. 108:381-387.

9. Chakraborty, S., Perrott, R., Charchar, M. J. d'A., Fernandes, C. D., and Kelemu, S. 1997. Biodiversity, epidemiology and virulence of Colletotrichum gloeosporioides. II. Genetic and pathogenic diversity in Colletotrichum gloeosporioides isolates from eight species of Stylosanthes. Trop. Grassl. 31:387-393.
10. Chakraborty, S., Perrott, R., Ellis, N., and Thomas, M. R. 1999. New aggressive Colletotrichum gloeosporioides strains on Stylosanthes scabra detected by virulence and DNA analysis. Plant Dis. 83:333-340.

11. Chakraborty, S., Thomas, M. R., and Ellis, N. 1996. A multivariate analysis of pathogenic variation in Colletotrichum gloeosporioides infecting the tropical pasture legume, Stylosanthes scabra. Phytopathology 86:283-289.

12. Davis, R. D., Irwin, J. A. G., and Cameron, D. F. 1984. Variation in virulence and pathogenic specialization of Colletotrichum gloeosporioides isolates from Stylosanthes scabra cvs. Fitzroy and Seca. Aust. J. Agric. Res. 35:653-662.

13. Digby, P. G. N., and Kempton, R. A. 1987. Multivariate Analysis of Ecological Communities. Chapman \& Hall, London.

14. Grof, B., Fernandes, C. D., and Fernandes, A. T. F. 2001. A novel technique to produce polygenic resistance to anthracnose in Stylosanthes capitata. Page 525 in: Proc. Int. Grassl. Congr., XIX. J. A. Gomide, W. R. S. Wilson, and S. C. daSilva, eds. FEALQ, Sao Pedro, Brazil.

15. Grof, B., Schultze-Kraft, R., and Müller, F. 1979. Stylosanthes capitata Vog., some agronomic attributes and anthracnose (Colletotrichum gloeosporioides Penz.). Trop. Grassl. 13:28-37.

16. Guodao, L., Phaikaew, C., and Stur, W. W. 1997. Status of Stylosanthes development in other countries. II. Stylosanthes development and utilisation in China and south-east Asia. Trop. Grassl. 31:460-466.

17. Hartigan, J. A. 1975. Clustering Algorithms. John Wiley \& Sons, New York.

18. Irwin, J. A. G., and Cameron, D. F. 1978. Two diseases in Stylosanthes spp. caused by Colletotrichum gloeosporioides in Australia, and pathogenic specialization within one of the causal organisms. Aust. J. Agric. Res. 29:305-317.

19. Irwin, J. A. G., Cameron, D. F., and Lenné, J. M. 1984. Responses of Stylosanthes to anthracnose. Pages 295-310 in: The Biology and Agronomy of Stylosanthes. H. M. Stace and L. A. Edye, eds. Academic Press, Sydney.

20. Kelemu, S., Badel, J. L., Moreno, C. X., Miles, J. W., Chakraborty, S., Fernandes, C. D., and Charchar, M. J. d'A. 1997. Biodiversity, epidemiology and virulence of Colletotrichum gloeosporioides. I. Genetic and pathogenic diversity in Colletotrichum gloeosporioides isolates from Stylosanthes guianensis. Trop. Grassl. 31:387-392.

21. Kelemu, S., Skinner, D. Z., Badel, J. L., Moreno, C. X., Rodriguez, M. X., Fernandes, C. D., Charchar, M. J. d'A., and Chakraborty, S. 1999. Genetic diversity in South American Colletotrichum gloeosporioides isolates from Stylosanthes guianensis, a tropical forage legume. Eur. J. Plant Pathol. 105:261-272.

22. Lenné, J. M. 1988. Variation in reaction to anthracnose within native Stylosanthes capitata populations in Minas Gerais, Brazil. Phytopathology 78:131-134.

23. Lenné, J. M., and Calderon, M. A. 1984. Disease and pest problems of Stylosanthes. Pages 279-293 in: The Biology and Agronomy of Stylosanthes. H. M. Stace and L. A. Edye, eds. Academic Press, Sydney.

24. Lenné, J. M., de Alvarez, A. V., and Torres, G. C. 1983. Pathogenic variation among isolates of Colletotrichum gloeosporioides affecting Stylosanthes spp. (Abstr.) Phytopathology 73:123.

25. Lenné, J. M., Thomas, D., de Andrade, R. P., and Vargas, A. 1984. Anthracnose of Stylosanthes capitata: Implications for future disease evaluations of indigenous tropical pasture legumes. Phytopathology 74 : 1070-1073.

26. Leonard, K. J. 1977. Selection pressures and plant pathogens. Ann. N.Y. Acad. Sci. 287:207-222.

27. Manners, J. M., and He, C. 1997. Recent advances in studies of anthracnose of Stylosanthes. IV. Molecular approaches to studies of Colletotrichum gloeosporioides causing anthracnose of Stylosanthes in Australia. Trop. Grassl. 31:435-444.

28. Miles, J. W., and Lascano, C. E. 1997. Status of Stylosanthes development in other countries. I. Stylosanthes development and utilisation in South America. Trop. Grassl. 31:454-459.

29. Miles, J. W., and Lenné, J. M. 1984. Genetic variation within a natural Stylosanthes guianensis, Colletotrichum gloeosporioides host-pathogen population. Aust. J. Agric. Res. 35:211-218.

30. Newton, A. C., and McGurk, L. 1991. Recurrent selection for adaptation of Erysiphe graminis f. sp. hordei to partial resistance of barley. J. Phytopathol. 132:328-338.

31. Pont, W., and Irwin, J. A. G. 1976. Colletotrichum leaf spot and stem canker of Stylosanthes spp. in Queensland. Aust. Plant Pathol. Soc. Newsl. 5(suppl.):S35.

32. Rojas, M. E., and Lascano, C. E. 1991. Competencia entre Andropogon gayanus and Stylosanthes capitata en pastures associadas bajo pastereo. Pasturas Trop. 13:2-8. 
33. Sicard, D., Buchet, S., Michalakis, Y., and Neema, C. 1997. Genetic variability of Colletotrichum lindemuthianum in wild populations of common bean. Plant Pathol. 46:355-365.

34. Stace, H. M., and Edye, L. A. 1984. The Biology and Agronomy of Stylosanthes. Academic Press, Sydney.

35. Thomas, D., Lascano, C. E., and Vera, R. R. 1987. A tropical pasture legume for poor soils. Span 30:1-4.

36. Vinijsanun, T., Irwin, J. A. G., and Cameron, D. F. 1987. Host range of three strains of Colletotrichum gloeosporioides from tropical pasture legumes, and comparative histological studies of interactions between type B disease-producing strains and Stylosanthes scabra (non-host) and S. guianensis (host). Aust. J. Bot. 35:665-677. 